\section{Maternidade atrás das grades: em busca da cidadania e da saúde. Um estudo sobre a legislação brasileira}

\author{
Motherhood behind bars: the struggle for citizens' \\ rights and health for women inmates and their \\ children in Brazil
}

\author{
La maternidad entre rejas: en búsqueda de la \\ ciudadanía y de la salud. Un estudio sobre la \\ legislación brasileña
}

Miriam Ventura ${ }^{1}$
Luciana Simas $1,2^{1,2}$
Bernard Larouzé

Resumo

Este estudo analisa as conexões entre saúde, direitos, legislação e políticas públicas a partir da pesquisa documental realizada no âmbito federal e nos estados do Rio Grande do Sul, Mato Grosso, Paraná e São Paulo, acerca das garantias legais das mulheres e seus filhos que vivem no cárcere. Busca instrumentalizar uma atuação garantista dos agentes públicos e dar visibilidade à problemática, diante das extremas vulnerabilidades e invisibilidade jurídica e administrativa da questão. Foram identificadas 33 normas legais, com pontos de tensão, como a possibilidade de prisão domiciliar e as disparidades quanto a prazos e condições de permanência das crianças no sistema penitenciário. A garantia legal constitucional do direito à amamentação é refletida nas regulamentações identificadas. Mas constatam-se ausências de outros aspectos relativos à maternidade na prisão, que se traduzem em dupla penalidade às mulheres, arbitrariamente estendida aos seus filhos. É necessária a ampliação e efetivação da regulamentação existente para prevenir e coibir as violações de direitos apontadas.

Prisões; Saúde Materno-Infantil; Direitos Reprodutivos; Legislação
Prisons; Maternal and Child Health;

Reproductive Rights; Legislation 


\section{Introdução}

As graves violações dos direitos das mulheres presas e de seus filhos nascidos no cárcere têm ganhado destaque pelo considerável crescimento do número de detentas no sistema prisional brasileiro (30\% entre o ano de 2009 a 2012) 1, bem como em razão de recomendações internacionais 2,3 sobre direitos humanos das mulheres, das crianças e sobre direitos reprodutivos.

$\mathrm{O}$ acesso aos cuidados de saúde de grupos discriminados socialmente é um aspecto central dessas recomendações, que admitem a garantia de direitos de família e reprodutivos das mulheres como elementos estratégicos e necessários para o efetivo cumprimento do direito à saúde. A importância da saúde reprodutiva e da criança é reiterada no documento Objetivos de Desenvolvimento do Milênio até 2015, firmado no ano 2000 nas Nações Unidas, com o estabelecimento de metas próprias a serem alcançadas pelos países. O Brasil tem avanços significativos, contudo persistem iniquidades em saúde que devem ser superadas em curto prazo ${ }^{4}$.

No tocante ao encarceramento feminino, as Regras de Bangkok, aprovadas no ano 2010 pela Assembleia Geral das Nações Unidas 5, estabelecem o consenso ético-jurídico internacional sobre o tratamento de mulheres presas e as medidas não privativas de liberdade. No documento são reafirmados direitos humanos relativos à maternidade, à família, à saúde da mulher, inclusive sexual e reprodutiva, e de seus filhos nos presídios. Estas regras representam uma resposta à inadequação de legislação e políticas criminais às condições femininas e à maternidade, com a reafirmação das responsabilidades dos países na implementação urgente nesse campo de leis e políticas de proteção e promoção dos direitos humanos.

A situação brasileira revela fragilidades das políticas criminais e sociais no que concerne à redução das desigualdades e ao fortalecimento da cidadania dessas mulheres e suas famílias. As sanções legais aplicadas nos processos criminais não têm favorecido a reconstrução de projetos de vida, a reinserção social, a redução das desigualdades 6, ou mesmo a preservação da saúde de mulheres e crianças, como previsto na Lei Nacional de Execução Penal (LEP) 7. O encarceramento tem representado um processo de exclusão, discriminação e estigmatização de segmentos pobres da população, com repercussões negativas em longo prazo e muitas vezes irreversíveis, para essas mulheres, seus companheiros e filhos 6 .

Dados do Departamento Penitenciário Nacional (Ministério da Justiça) apontam que em 2012 havia 31.640 mulheres presas no Brasil, que representam $6 \%$ da população carcerária brasi- leira, incluindo as que se encontram nos presídios, cadeias públicas, distritos policiais e delegacias brasileiras. A maioria das presas é jovem, tem filhos, provém de classes populares e possui um baixo nível educacional. Além das características socioeconômicas desfavoráveis, $34 \%$ são presas provisórias, ainda não condenadas pelo Poder Judiciário, e na maioria responde por condutas menos gravosas relacionadas ao tráfico de entorpecentes, como o transporte de pequenas quantidades de drogas para o companheiro preso, com condenações em penas no patamar mínimo (Departamento Penitenciário Nacional, Ministério da Justiça. Infopen: estatísticas. http://por tal.mj.gov.br/main.asp?View=\%7BD574E9CE3C7D-437A-A5B6-22166AD2E896\%7D\&Team= \&params $=$ itemID $=\% 7 \mathrm{~B} 2627128 \mathrm{E}-\mathrm{D} 69 \mathrm{E}-45 \mathrm{C} 6$ 8198-CAE6815E88D0\%7D;\&UIPartUID=\%7B28 68BA3C-1C72-4347-BE11-A26F70F4CB26\%7D, acessado em 12/Out/2013).

Embora a LEP garanta a assistência à saúde e preveja que os estabelecimentos penitenciários destinam-se a presos condenados a regime fechado, enquanto que as cadeias públicas recolheriam presos provisórios, em diversos estados brasileiros essa determinação não é respeitada, encontrando-se presas ainda sem julgamento em penitenciárias. Igualmente irregular é a manutenção das presas em delegacias e distritos policiais após o início do processo penal, pois a permanência nestes estabelecimentos deveria ser apenas durante o período de investigação policial para o oferecimento da denúncia criminal pelo Ministério Público. Por isso, neste estudo, será considerada "mulher presa" toda aquela que se encontre penalmente restrita de liberdade, tendo sido condenada a regime fechado ou sendo apenas detida provisoriamente esperando julgamento.

O inquérito preliminar ao projeto de pesquisa multidisciplinar Saúde Materno-infantil nas Prisões do Brasil (Leal MC, Sanchez AR, Larouzè B, Castro VD, Santos M, Pereira APE, et al. Relatório parcial do Projeto de Pesquisa Saúde Materno-Infantil nas Prisões do Brasil. Rio de Janeiro: Escola Nacional de Saúde Pública Sergio Arouca, Fundação Oswaldo Cruz; 2014), que inclui este estudo legislativo, além dos componentes jurisprudencial, de saúde, psicossocial e arquitetônico, apontou que, em dezembro de 2012, $2 \%$ do total das mulheres encarceradas encontravam-se grávidas e, no período de um ano, 272 presas tiveram seus filhos enquanto encarceradas, tendo sido realizado o parto no sistema público de saúde. No país, cerca de 400 crianças, a maioria com menos de um ano, viviam com suas mães em prisões. Em que pese a possibilidade de convivência entre mãe e filho ser um importante avanço no 
sistema, as presas expressam situação de angústia em razão de inúmeros fatores característicos de uma prisão que limitam uma convivência saudável, como o ambiente frequentemente insalubre. Afligem-se também diante da ausência de resposta do sistema de justiça sobre seu processo criminal, possibilitando, por exemplo, sua saída do cárcere, ou do destino de seus filhos após o período de permanência no cárcere.

Os resultados preliminares revelam condições precárias relativas aos ambientes de vida e aos cuidados de saúde materna e infantil (Leal MC, Sanchez AR, Larouzè B, Castro VD, Santos M, Pereira APE, et al. Relatório parcial do Projeto de Pesquisa Saúde Materno-infantil nas Prisões do Brasil. Rio de Janeiro: Escola Nacional de Saúde Pública Sergio Arouca, Fundação Oswaldo Cruz; 2014). Análises em curso incluem, entre outros, a avaliação do desenvolvimento psicomotor das crianças nascidas durante o encarceramento da mãe e que vivem nas prisões. Este é um aspecto importante, considerando que estudo realizado nas prisões na Argentina revelou que cerca de $40 \%$ das crianças abaixo de quatro anos que viviam com suas mães nas prisões apresentavam transtornos emocionais ${ }^{8}$. A invisibilidade social e a ausência de medidas institucionais de proteção legal dos direitos dessas crianças nos estabelecimentos prisionais apontam para um tipo de penalidade estendida aos filhos das presas, e preocupantemente admitida como inevitável, em contradição com direito fundamental constitucional, assegurado também na LEP, de que "nenhuma pena passará da pessoa do condenado" (Constituição Federal).

A maioria das instituições penitenciárias não está adequada às necessidades femininas 9 , pari passu os cuidados com a saúde sexual e reprodutiva, programas e ações públicas de apoio à maternidade e às famílias são negligenciados pelo Estado. Em geral, o acesso à saúde possui sérias limitações, como apontado em outros estudos mais recentes e gerais 10 . No contexto brasileiro, as mulheres em situação carcerária têm sua vulnerabilidade aumentada em razão de obstruções ao acesso a serviços legais, de saúde e social, além das degradantes condições ambientais carcerárias. Essa situação é estendida aos seus filhos, reproduzindo um círculo vicioso de persistente violação de direitos humanos.

No tocante à maternidade nas prisões, os raros estudos jurídicos identificados investigam limitadamente o direito ao aleitamento materno 11,12 , previsto no art. 5o, inc. L, da Constituição Federal, praticamente sem considerar a mãe também como cidadã e sujeito de direitos, mas como mera fonte de alimentação do bebê 11 . Por sua vez, o estudo de Rita 9 associa os referenciais legais com as ações institucionais na prisão, afirmando que não há uma correspondência entre o expresso nos instrumentos normativos e a realidade vivenciada pela mulher-mãe presa. Contudo, não tem como objeto específico a análise pormenorizada da legislação.

Nesse sentido, revelou-se a necessidade de um levantamento mais amplo da proteção legal existente no ordenamento jurídico nacional, especialmente relacionado aos direitos reprodutivos relativos à maternidade, às relações familiares, à mulher e à criança que vivem no cárcere sob a responsabilidade do Estado. Assim, com o propósito de mapear esta conjuntura político-jurídica brasileira, foi realizada pesquisa documental no âmbito legislativo federal e dos estados do Mato Grosso, Paraná, Rio Grande do Sul e São Paulo, que totalizam $50 \%$ dos encarceramentos femininos no Brasil.

Nossa proposta diferencial de pesquisa buscou ampliar a compreensão do fenômeno pesquisado no âmbito do projeto de pesquisa multidisciplinar Saúde Materno-infantil nas Prisões do Brasil, e instrumentalizar gestores da saúde e profissionais jurídicos, na medida em que sistematiza a lógica normativa contemporânea acerca do tema pesquisado.

\section{Saúde, direito e legislação: a busca do círculo virtuoso}

O conjunto de normas legais nacionais e internacionais tem se revelado um instrumento importante na garantia de direitos. As leis estabelecidas democraticamente constituem proposições públicas que envolvem obrigações para com os outros e garantias pessoais contra descumprimentos 13. Os documentos internacionais de direitos humanos igualmente revelam-se importantes no que se refere à possibilidade de influírem positivamente nas leis e jurisprudências dos países (Barsted, 1998, apud Piovesan \& Pirotta 14).

A saúde na atualidade é compreendida na agenda pública internacional como "uma complexa produção social, em que os resultados para o bem estar da humanidade são cada vez mais o fruto de decisões políticas incidentes sobre os seus determinantes sociais [...] que engendram formas de acesso à alimentação, à educação, ao trabalho, renda, lazer e ambiente adequado, entre outros aspectos" 15 (p. 141).

Portanto, admitir as conexões entre saúde, direitos, legislação e políticas públicas é reconhecer a estreita vinculação da saúde com o grau de cidadania e justiça social vivenciada. E, assim objetivar a conformação de um sistema jurídicolegal e político favorável e efetivo à redução das 
desigualdades e à melhoria da situação de saúde. As instâncias internacionais de direitos humanos há décadas incluem a revisão e reforma das legislações nacionais, como componente central no enfrentamento de questões de saúde, como, por exemplo, a garantia de igualdade entre os gêneros, a autonomia reprodutiva das mulheres, a descriminalização do aborto como favorável à redução da morte materna, entre outras 2,3.

Inicialmente, a relação da saúde com a legislação concentrava-se na regulamentação de medidas de controle (imunizações obrigatórias, quarentena etc.), buscando-se garantir liberdades individuais e estabelecer critérios para as intervenções estatais, nos casos de uma necessidade específica 16. Mais recentemente, a partir da definição contemporânea de saúde e do reconhecimento de suas determinantes sociais 17 , ampliam-se as funções do Direito e da Legislação na saúde.

Nesse sentido, têm sido destacados, pelo menos, três conjuntos de leis, objetos de preocupação da saúde pública, que devem ser contemplados na abordagem legislativa do problema de mães e crianças vivendo na prisão. As leis protetoras e antidiscriminatórias, que estabelecem garantias específicas, visando mitigar os efeitos negativos da discriminação e a vulnerabilidade (pessoal, programática e social) de determinados grupos; as leis que regulamentam o acesso a bens, serviços e informações de saúde e sociais, definindo as responsabilidades do Estado e os canais efetivos de acesso do cidadão às políticas públicas; e as leis criminais e os sistemas corretivos 18

As novas abordagens da saúde pública aprofundam a relação do Direito com a saúde 19,20 e, consequentemente, ampliam-se as funções da legislação. Nesse sentido, o debate acerca da regulamentação sobre a maternidade atrás das grades e a busca da cidadania e da saúde dessas mulheres e seus filhos incluem-se no âmbito desta discussão. A partir dessas perspectivas mais amplas da conexão entre saúde e direito é que se buscou analisar a legislação brasileira que contempla as mães encarceradas que vivem com suas crianças nas prisões.

\section{Material e método}

O estudo qualitativo combinou a técnica de pesquisa bibliográfica e documental nas bases do SciELO e BVS e fontes governamentais.

A pesquisa documental objetivou identificar a produção dos Legislativos Federal e dos estados do Mato Grosso, Paraná, Rio Grande do Sul e São Paulo, que possuem competência em maté- ria penitenciária e de saúde (art. 24 Constituição Federal); selecionando-se todos os tipos normativos disponíveis (leis, decretos etc.), vigentes até 17 de fevereiro de 2013. Também foram pesquisados os atos administrativos normativos (portarias, decretos, regulamentos) dos Executivos Federal e Estaduais, que possuem competências deliberativa e consultiva para formular a política criminal e regras sobre funcionamento dos estabelecimentos penitenciários. Não foram pesquisadas normas municipais, pois esses entes federativos não possuem competência para tratar da matéria penal.

No sistema legal brasileiro, há uma hierarquia estabelecida entre as normas legais (art. 59 Constituição Federal). Assim, as Leis Ordinárias, Decretos, Resoluções, Portarias devem se submeter à Constituição e às normas que lhes são superiores.

As informações coletadas foram sistematizadas em um banco de dados, que consolidou leis relativas à maternidade, ao nascimento e ao crescimento da criança no ambiente carcerário.

O método utilizado para análise do material legislativo foi o da interpretação jurídica sistemática, que leva em conta o sistema em que se insere o documento legal identificado, e "procura estabelecer a concatenação entre este e os demais elementos da própria Lei, do respectivo campo do direito ou do ordenamento jurídico geral" 21 (p. 9). Tal método permite "averigua[r] todas as disposições pertinentes ao mesmo objeto e entende $[\mathrm{r}]$ o sistema jurídico de forma harmoniosa e interdependente" 21 (p. 9), e analisar a produção legislativa em seu contexto com outras normas, afastando-se da interpretação hermenêutica tradicional, que não considera elementos exteriores.

Para a busca sistemática, foram adotados descritores, como presa e filho; adoção e presa; amamentação e presa; creche e presa; poder familiar e presa; dentre outros. As bases de dados utilizadas foram: Planalto (Pesquisa de Legislação), LexML (Rede de Informação Legislativa e Jurídica) do Ministério da Justiça, Saúde Legis (Sistema de Legislação de Saúde do Ministério da Saúde), Câmara dos Deputados, Senado Federal, Assembleia Legislativa do Paraná (Casa Civil - Sistema Estadual de Legislação), Assembleia Legislativa do Estado do Mato Grosso, Secretaria de Saúde do Estado do Mato Grosso, Assembleia Legislativa do Estado de São Paulo, Assembleia Legislativa do Estado do Rio Grande do Sul. Destaca-se, entre os achados e como uma das fontes da pesquisa, a publicação Legislação da Saúde no Sistema Penitenciário 22.

No desenvolvimento do estudo, revelou-se importante realizar buscas complementares em outras fontes institucionais oficiais, tais como: 
Departamento de Execução Penal do Estado do Paraná; Secretaria de Segurança Pública do Paraná; Secretaria de Saúde do Paraná; Secretaria de Justiça, Cidadania e Direitos Humanos do Paraná; Ministério Público do Estado do Paraná; Secretaria de Segurança Pública do Mato Grosso; Secretaria de Estado de Justiça e Direitos Humanos do Mato Grosso; Secretaria de Estado e Saúde do Mato Grosso; Secretaria de Administração Penitenciária de São Paulo; Secretaria de Segurança Pública de São Paulo; Secretaria de Justiça e dos Direitos Humanos do Rio Grande do Sul; Superintendência dos Serviços Penitenciários do Rio Grande do Sul; Ministério da Justiça; Conselho Nacional de Política Criminal e Penitenciária (CNPCP), que têm competências deliberativa e consultiva junto ao Ministério da Justiça sobre política criminal e na formulação das regras sobre as condições dos estabelecimentos penitenciários; bem como sites oficiais dos governos do Paraná, Mato Grosso, Rio Grande do Sul e São Paulo.

A estratégia de busca incluiu o uso da palavra-chave isoladamente e depois pela associação de duas ou mais palavras-chave, de modo a aumentar as variáveis de especificidade e exaustividade, que influenciam todo o processo de recuperação da informação. A formulação da busca se adequou aos recursos de pesquisa de cada base de dados selecionada, em função da heterogeneidade entre os sítios analisados. Na busca por associação de palavras foram utilizados os operadores booleanos, o que permitiu de forma mais rápida e direcionada identificar as normas objeto da pesquisa.

Uma dificuldade foi a grande variação de possibilidades de busca entre as diferentes bases consultadas, pois se apresentam de formas díspares, exigindo que descritores extras fossem utilizados a fim de obter normas pertinentes ao objeto pesquisado. Outro aspecto metodológico relevante é que algumas bases legislativas já fazem uma pré-seleção das normas em destaque acerca do tema, bem como limitam a pesquisa ao ementário e não ao texto integral da lei.

Em virtude da importância no ordenamento jurídico nacional - seja pela hierarquia ou pelo tratamento dado ao tema pesquisado -, algumas normas foram a priori selecionadas. São elas: a Constituição Federal e as Constituições dos estados-membros supramencionados, o Código Penal, o Código de Processo Penal, a LEP, o Código Civil e o Estatuto da Criança e do Adolescente.

Leis que alteraram estatutos legais vigentes não foram contabilizadas separadamente, considerando-se que a norma modificada já havia sido contabilizada, como a Lei no 12.313/2010, que deu nova redação à LEP (Lei no 7.210/1984).
Os documentos foram classificados com informações, como: descritor utilizado, título, ementa, tipo, número, ano, esfera de governo, Unidade da Federação e órgão. Em seguida, foi realizada nova seleção, excluindo aqueles não diretamente relacionados ao escopo da pesquisa.

Por fim, foram elaborados quadros sistematizando os resultados obtidos no levantamento legislativo, divididos em quatro planos: normas federais, oriundas do Congresso Nacional, e do Poder Executivo; normas estaduais, com um quadro próprio para a legislação do Estado de São Paulo, diante da prevalência do número de documentos encontrados, e outro com as oriundas dos outros estados pesquisados.

\section{Resultados e discussão}

Foi identificado o total de 33 normas, entre Leis, Portarias e outras normas administrativas, que permitiu caracterizar as principais preocupações dos legisladores brasileiros no tocante à maternidade nas prisões. Considerando-se que a pesquisa não se limitou a um único período histórico, podemos observar, de início, uma baixa quantidade de normas jurídicas acerca do tema.

No âmbito federal, por exemplo, foram encontradas 12 normas, sendo 6 oriundas do Poder Legislativo e a outra metade do Executivo, conforme quadros abaixo. A seleção quanto à fonte produtora permite identificar que o Executivo vem, mesmo que timidamente, buscando dar operacionalidade às normas jurídicas sobre maternidade na prisão inscritas nas leis gerais, por meio de construção de políticas públicas voltadas para esse segmento social. Em contrapartida, há poucas iniciativas do Poder Legislativo no sentido de regulamentar a situação da maternidade na prisão em diploma legal específico que estabeleça regras nacionais obrigatórias, reduzindo a discricionariedade dos Executivos, federal e estaduais, sobre o tema (Tabelas 1 e 2).

A Constituição Federal de 1988 inovou ao prever a garantia de condições de permanência da presidiária com seus filhos durante o período de amamentação. Pelo princípio da simetria correlacionado ao modelo constituinte brasileiro, as constituições estaduais refletiram essa regra, o que ficou constatado nos estados pesquisados.

A partir de suas constituições, os estados deveriam disciplinar a situação das mães e seus filhos em presídios de maneira mais concreta através da regulamentação infraconstitucional. Todavia, o que se constatou foi uma baixa (ou ausência de) regulamentação específica sobre a matéria em alguns locais, como no caso do Rio Grande do Sul, no qual não foram localizados 
Tabela 1

Legislação federal, produzida no âmbito do Poder Legislativo, que contempla direitos para mães presas com seus filhos.

\begin{tabular}{|c|c|c|}
\hline Título & Ementa & Destaques (artigos) \\
\hline $\begin{array}{l}\text { Constituição da República } \\
\text { Federativa do Brasil de } \\
1988\end{array}$ & & $\begin{array}{l}\text { Direitos fundamentais das presidiárias a estabelecimento adequado à sua condição } \\
\text { feminina, à amamentação de seus filhos (Art. 5o. XLVIII, L), e convivência familiar (Art. 227). }\end{array}$ \\
\hline $\begin{array}{l}\text { Decreto-Lei no } 2.848 \text {, de } 7 \\
\text { de dezembro de } 1940\end{array}$ & Código Penal & Cumprimento da pena em estabelecimento apropriado às mulheres (Art. 37). \\
\hline $\begin{array}{l}\text { Decreto-Lei no } 3.689 \text {, de } 3 \\
\text { de outubro de } 1941\end{array}$ & $\begin{array}{l}\text { Código de Processo } \\
\text { Penal }\end{array}$ & Substituição de prisão preventiva pela domiciliar (Art. 318). \\
\hline $\begin{array}{l}\text { Lei no } 7.210 \text {, de } 11 \text { de julho } \\
\text { de } 1984\end{array}$ & $\begin{array}{l}\text { Institui a Lei de } \\
\text { Execução Penal }\end{array}$ & $\begin{array}{c}\text { Acompanhamento médico à mulher e ao recém-nascido (Art. 14. § 3ㅇ). Obrigatoriedade de } \\
\text { berçário, local para amamentação, no mínimo, até } 6 \text { (seis) meses de idade (Art. 83. § 20). } \\
\text { Obrigatoriedade de local para gestante e parturiente, e creche para crianças maiores de } 6 \\
\text { (seis) meses e menores de } 7 \text { (sete) anos (Art. 89). Benefício do regime aberto em residência } \\
\text { particular para condenada com filho menor ou deficiente físico ou mental; condenada } \\
\text { gestante (Art. 117). }\end{array}$ \\
\hline $\begin{array}{l}\text { Lei no } 10.406 \text {, de } 10 \text { de } \\
\text { janeiro de } 2002\end{array}$ & Institui o Código Civil & $\begin{array}{l}\text { Possibilidades de suspensão do poder familiar ao pai ou à mãe condenados por sentença } \\
\text { irrecorrível, em virtude de crime cuja pena exceda a dois anos de prisão (Art. 1.583, § 5o; } \\
\text { art. } 1.637 \text { e 1.638). }\end{array}$ \\
\hline $\begin{array}{l}\text { Lei no } 8.069 \text {, de } 13 \text { de julho } \\
\text { de } 1990\end{array}$ & $\begin{array}{l}\text { Dispõe sobre o } \\
\text { Estatuto da Criança e } \\
\text { do Adolescente }\end{array}$ & $\begin{array}{l}\text { Condições adequadas ao aleitamento e convivência com a mãe presa (Art. 9으). Condições } \\
\text { dignas e proteção integral à criança (Art. 3ㅇ, 4으, 5ㅇ e 7으). Liberdade e convivência da criança } \\
\text { com a mãe (Art. } 16 \text { e 19). Poder familiar e condenação criminal (Art. 23). Oitiva dos pais nos } \\
\text { processos de adoção e guarda de filhos (Art. 158). }\end{array}$ \\
\hline
\end{tabular}

dispositivos legislativos sobre o tema, além da Constituição estadual.

A falta de iniciativa legislativa acerca do tema indica diversos aspectos desfavoráveis à garantia de direitos que afetam à saúde destes segmentos. Ressaltam-se a ausência de interesse em disciplinar uma questão tão polêmica; a "invisibilidade social”, jurídica e administrativa das crianças vivendo com suas mães na prisão; e a carência de regulamentação apropriada dos direitos das mães e crianças, bem como dos deveres e procedimentos específicos a serem adotados pela autoridade penitenciária em relação a esta população, sob a exclusiva responsabilidade do Estado.

\section{Legislação federal}

Os destaques atuais na legislação federal dizem respeito à possibilidade de prisão domiciliar, a partir da reforma processual penal de 2011, nos casos de prisão provisória quando a presa for “imprescindivel aos cuidados especiais de pessoa menor de 6 (seis) anos de idade ou com deficiência"; ou for "gestante a partir do 7o (sétimo) mês de gravidez ou sendo esta de alto risco". Essa autorização legislativa, condizente com um olhar específico para a questão de gênero, se coaduna com a possibilidade prevista na LEP de recolhi- mento domiciliar na fase de execução da pena, também quando a condenada for gestante ou tiver filho menor ou deficiente físico ou mental.

Em 2009, a LEP sofreu alterações, notadamente pela Lei no 11.942, que fixou expressamente o período de, no mínimo, até 6 (seis) meses de idade para permanência da criança com a mãe presa em berçários. Por sua vez, a Resolução CNPCP no 04, de 15 de julho de 2009, estabelece um prazo de até um ano e seis meses: "visto que a presença da mãe nesse período é considerada fundamental para o desenvolvimento da criança, principalmente no que tange à construção do sentimento de confiança, otimismo e coragem, aspectos que podem ficar comprometidos caso não haja uma relação que sustente essa primeira fase do desenvolvimento humano; esse periodo também se destina para a vinculação da mãe com sua(seu) filha(o) e para a elaboração psicológica da separação e futuro reencontro".

A penitenciária feminina deverá possuir seção para gestante/parturiente e creche para abrigar crianças "desamparadas" maiores de 6 (seis) meses e menores de 7 (sete) anos. A lei não esclarece o que seria caracterizado como desamparo, não fazendo nenhuma referência econômica ou afetiva. Defendemos que a interpretação deste dispositivo da LEP não deve ser restritiva, por ser 
Tabela 2

Legislação federal, produzida no âmbito do Poder Executivo, que contempla direitos para mães presas com seus filhos.

\begin{tabular}{|c|c|c|}
\hline Título & Ementa & Destaques (artigos) \\
\hline $\begin{array}{l}\text { Resolução CNPCP no } 14 \text {, de } \\
11 \text { de novembro de } 1994\end{array}$ & $\begin{array}{l}\text { Regras Mínimas para o } \\
\text { Tratamento do Preso. }\end{array}$ & $\begin{array}{c}\text { Condições para permanência dos filhos com as presas durante o período } \\
\text { de amamentação (Art.7으, §§ 1ㅇ e 2ㅇ). Dotação de material obstétrico no } \\
\text { estabelecimento prisional para caso de emergência (Art.17). }\end{array}$ \\
\hline $\begin{array}{l}\text { Resolução CNPCP no 04, de } \\
15 \text { de julho de } 2009\end{array}$ & $\begin{array}{l}\text { Disciplina a permanência } \\
\text { dos filhos das presas em } \\
\text { ambientes prisionais. }\end{array}$ & $\begin{array}{l}\text { Orientações para permanência e encaminhamento dos filhos das presas (Art.2ㅇ). } \\
\text { Permanência no mínimo até um ano e seis meses junto às mães encarceradas } \\
\text { (Art.1ㅇ). Processo gradual de separação (Art.3ㅇ). Possibilidades para abrigo das } \\
\text { crianças: família ampliada, família substituta ou instituições (Art.4으). Berçário para } \\
\text { crianças de até dois anos (Art.6o) Possibilidade de permanência de crianças de } \\
\text { dois a sete anos junto às mães na unidade prisional (Art.7o). Alimentação (Art.5o). } \\
\text { Visita de familiares e pais presos (Art.9ㅇ). Licença da atividade laboral (Art.10). } \\
\text { Responsabilidade da União e dos Estados para construir e manter penitenciárias } \\
\text { femininas com berçário (Art.8o). Possibilidade de alteração dos prazos e condições } \\
\text { de permanência de crianças na unidade prisional (Art.12). }\end{array}$ \\
\hline $\begin{array}{l}\text { Resolução CNPCP no 09, de } \\
18 \text { de novembro de } 2011\end{array}$ & $\begin{array}{l}\text { Diretrizes Básicas para } \\
\text { Arquitetura Penal. }\end{array}$ & Seção para gestantes e parturientes; creches - módulo de berçário (Anexo V). \\
\hline $\begin{array}{l}\text { Resolução CNPCP no 3, de } \\
1 \text { de junho de } 2012\end{array}$ & $\begin{array}{c}\text { Recomendação sobre o uso } \\
\text { de algema. }\end{array}$ & $\begin{array}{l}\text { Proibido uso de algemas ou outros meios de contenção durante o parto e no } \\
\text { período de repouso subsequente (Art. 3ㅇ). Recomendação aos profissionais da } \\
\text { saúde que noticiem formalmente o uso indevido (Art. } 5 \text { 으). }\end{array}$ \\
\hline $\begin{array}{l}\text { Portaria MS/MJ no } 1.777 \text {, de } \\
9 \text { de setembro de } 2003\end{array}$ & $\begin{array}{c}\text { Plano Nacional de Saúde no } \\
\text { Sistema Penitenciário. }\end{array}$ & $\begin{array}{l}\text { Saúde da mulher. Assistência ao pré-natal, parto e puerpério em } 100 \% \text { das unidades } \\
\text { penitenciárias. Não há referência a pediatra, ou acompanhamento das crianças } \\
\text { (Anexo I). }\end{array}$ \\
\hline $\begin{array}{l}\text { Plano Nacional de Política } \\
\text { Criminal e Penitenciária }\end{array}$ & $\begin{array}{l}\text { Plano Nacional de Política } \\
\text { Criminal e Penitenciária - } \\
\text { CNPCP/MJ 26/04/2011. }\end{array}$ & $\begin{array}{c}\text { Assistência pré-natal e a existência de espaços e serviços específicos para gestantes } \\
\text { durante a gestação e no período de permanência dos filhos no ambiente carcerário } \\
\text { (Medida 5). }\end{array}$ \\
\hline
\end{tabular}

CNPCP: Conselho Nacional de Política Criminal e Penitenciária.

norma garantidora de direitos humanos, devendo efetivar da melhor forma possível o "princípio do melhor interesse da criança”.

De todo modo, a LEP prevê expressamente atendimento por pessoal qualificado, de acordo com as diretrizes adotadas pela legislação educacional e em unidades autônomas; bem como horário de funcionamento que garanta a melhor assistência à criança e à sua responsável.

Destaca-se no âmbito federal a atuação normativa do CNPCP, atento à questão da maternidade nos presídios em diferentes Resoluções. Ao disciplinar regras mínimas para o tratamento do preso, diretrizes básicas para arquitetura penal, bem como o uso de algemas, foram pontuados aspectos com enfoque de gênero. Além disso, a Resolução no 04/2009, referida acima, disciplina especificamente a permanência dos filhos das presas em ambientes prisionais.

A competência legislativa referente ao direito penitenciário é concorrente, de acordo com o artigo 24, inciso I da Constituição Federal. O que significa dizer que o poder de produzir leis a respeito dessa matéria é distribuído entre a União Federal e os estados-membros, cabendo àquela estabelecer regras gerais a serem observadas pelos demais. Portanto, esta Resolução do CNPCP, juntamente com as disposições da LEP, seriam as regras federais específicas direcionadoras para a atuação e normatização por todos os demais entes federativos.

A Resolução CNPCP no 04/2009 apresenta grandes avanços no tocante à estada, permanência e encaminhamento de seus filhos. São previstas como orientações principiológicas: I. respeito à "ecologia do desenvolvimento humano", que permita espaço adequado ao "desenvolvimento infantil em padrões saudáveis e uma relação de qualidade entre a mãe e a criança”; II. valorização prioritária da "continuidade do vínculo materno"; III. "compreensão da amamentação", a partir de seus impactos físicos e psicológicos, tanto para a mãe, quanto para a criança, "tratada de forma privilegiada". 
A referida resolução regula, de maneira fundamentada, desde o tempo de permanência da mãe com seu filho, até aspectos como lar de destino da criança, espaço de berçário, alimentação, visita de familiares e pais presos, construção de unidades prisionais femininas, e capacitação dos servidores públicos do sistema prisional sobre a questão. Destaca-se a previsão de processo de separação da mãe com seu filho, que deve ser iniciado após a criança completar um ano e seis meses de idade, ser gradual e durar até seis meses. A ordem de possibilidades para a escolha do futuro lar para a criança deve ser família ampliada, seguida da família substituta ou instituições, permitindo-se que os prazos e condições de permanência de crianças nas unidades prisionais possam ser alterados, a partir da avaliação dos técnicos submetidos à decisão do juiz competente.

A Resolução CNPCP no 04/2009 inova ao garantir um período de seis meses de licença de atividade laboral para fins de remição da pena, para aquelas mulheres que estiverem trabalhando na unidade prisional durante a gestação. Como já previsto na LEP, o trabalho permite uma redução da pena na proporção de cada três dias trabalhados menos um dia de pena. Assim, o direito à licença miniza uma das dificuldades para a convivência entre a mãe e seu filho, pois em muitos casos a criança tem que ser afastada para garantir a manutenção da atividade laboral da presa. Contudo, é conveniente uma ressalva, levando-se em consideração que grande número de mulheres que trabalham no sistema penitenciário encaminha parte de sua pequena remuneração para suas famílias fora da prisão. A previsão da licença limitada para fins de remição não supre a necessidade financeira, explicitando a lacuna de políticas públicas de assistência voltadas para essa parcela da população.

Após a conclusão da pesquisa identificouse a aprovação de duas novas normas legais. A Portaria Interministerial MJ/GM no 210, de 16 de janeiro de 2014, instituiu a Política Nacional de Atenção às Mulheres em Situação de Privação de Liberdade de e Egressas do Sistema Prisional PNAMPE.

A Lei no 12.962, de 8 de abril de 2014, alterou o Estatuto da Criança e do Adolescente (ECA), introduzindo importantes avanços no que se refere aos direitos de família e à situação prisional. As alterações incluíram dispositivo legal que trata da impossibilidade da perda do poder familiar por falta ou carência de recursos materiais dos familiares e três garantias legais. A primeira refere-se ao direito à assistência social, obrigando a inclusão de crianças e adolescentes em programas oficiais de auxílio, quando o juiz cons- tatar a situação de pobreza. Tal dispositivo pode favorecer a manutenção dos vínculos familiares nessa situação de ausência de recursos materiais, comum na realidade penitenciária. A segunda tem caráter anti-discriminatória e previne que a destituição do poder familiar se dê em razão de um preconceito comum, ou seja, de que quem comete crime não tem o direito à maternidade e paternidade; e dispõe que somente no caso de condenação por crime doloso contra o próprio filho é possível a destituição do poder familiar. A terceira é de natureza processual, garante nacionalmente a obrigatoriedade da citação pessoal dos pais privados de liberdade, bem como a nomeação de defensor para esses casos, e que os pais presidiários sejam levados à autoridade judicial para que sejam ouvidos sobre a situação dos filhos. A alteração legal é bastante relevante, considerando as queixas recorrentes das mulheres presas de perda do poder familiar sem que sejam ouvidas, ou mesmo, sem o conhecimento dessas.

\section{Legislação estadual}

No tocante às fontes reguladoras, tal como no âmbito federal, a iniciativa por parte do gestor público também pôde ser observada no âmbito dos estados do Mato Grosso, Paraná e Rio Grande do Sul, como apresentado na Tabela 3.

Apenas no Paraná, o legislador ordinário estadual se manifestou acerca do tema. Trata-se de uma lei específica a respeito de a Creche Pré-Escolar Cantinho Feliz, na Penitenciária Feminina, abrigar crianças do período de aleitamento até seis anos, quando não possuírem condições de sobrevivência com a família, e permite às mães presas trabalharem com benefício financeiro e redução de pena. Nesse estado, há também referências sobre o assunto no Estatuto Penitenciário e Regimento Interno do Departamento Penitenciário. Tal como no Estado do Paraná, no Rio Grande do Sul está prevista possibilidade da permanência da criança com sua mãe até os seis anos de idade.

O Mato Grosso disciplina, apenas no Regimento Interno Padrão dos Estabelecimentos Prisionais, a existência de locais internos e externos para os cuidados pré-natais e maternidade, bem como "para guarda de nascituro e lactante".

Em São Paulo, foi intensa a produção legislativa, como demonstra o quadro a seguir, em comparação com os outros estados. Com exceção da Constituição Estadual, todas as demais 13 normas existentes são decretos governamentais, criando ou reorganizando penitenciárias femininas. $\mathrm{O}$ atendimento aos filhos das presas nos Centros de Reintegração e Atendimento à Saúde, 
Tabela 3

Legislação dos estados do Mato Grosso, Paraná e Rio Grande do Sul, que contempla direitos para mães presas com seus filhos.

\begin{tabular}{|c|c|c|c|}
\hline Título & Ementa & $\begin{array}{l}\text { Unidade da } \\
\text { Federação }\end{array}$ & Destaques (artigos) \\
\hline $\begin{array}{l}\text { Constituição do Estado do } \\
\text { Mato Grosso de } 1989\end{array}$ & & $\begin{array}{l}\text { Mato } \\
\text { Grosso }\end{array}$ & $\begin{array}{c}\text { Creche, independente e anexa ao estabelecimento prisional (Art.87. } \\
\text { referência ao art. 5ㅇ, L, da Constituição Federal). }\end{array}$ \\
\hline $\begin{array}{l}\text { Decreto no } 8.260 \text {, de } 20 \text { de } \\
\text { janeiro de } 2004\end{array}$ & $\begin{array}{c}\text { Regimento Interno Padrão dos } \\
\text { Estabelecimentos Prisionais } \\
\text { da Secretaria de Justiça e } \\
\text { Segurança Pública do Estado } \\
\text { do Mato Grosso }\end{array}$ & $\begin{array}{l}\text { Mato } \\
\text { Grosso }\end{array}$ & $\begin{array}{l}\text { Local interno e externo para os cuidados pré-natais e maternidade; } \\
\qquad \text { e para "guarda" de nascituro e lactante (Art. 21). }\end{array}$ \\
\hline $\begin{array}{l}\text { Constituição do Estado do } \\
\text { Paraná de } 1989\end{array}$ & & Paraná & $\begin{array}{l}\text { Creches, assegurando-se às mães internas o direito a permanecer } \\
\text { com o filho no período de aleitamento (Art. 254). }\end{array}$ \\
\hline $\begin{array}{l}\text { Lei no } 9.304 \text {, de } 19 \text { de junho } \\
\text { de } 1990\end{array}$ & $\begin{array}{l}\text { Cria a Creche Pré-Escolar } \\
\text { Cantinho Feliz, na Penitenciária } \\
\text { Feminina e adota providências }\end{array}$ & Paraná & $\begin{array}{l}\text { Atendimento do período de aleitamento até } 06 \text { (seis) anos, quando } \\
\text { não possuir condições de sobrevivência com a família. Normas } \\
\text { sobre as condições de atendimento à criança e à mãe (Art. 1ㅇ e 20). }\end{array}$ \\
\hline $\begin{array}{l}\text { Decreto no } 1.276 \text {, de } 31 \text { de } \\
\text { março de } 1995\end{array}$ & $\begin{array}{l}\text { Estatuto Penitenciário do } \\
\text { Estado do Paraná }\end{array}$ & Paraná & $\begin{array}{c}\text { Creche e Pré-Escola em regime fechado ou semiaberto, para } \\
\text { crianças de até seis anos de idade. § 1ㅇ Prevê um pedagogo e um } \\
\text { pediatra (Art. 17). }\end{array}$ \\
\hline $\begin{array}{l}\text { Resolução no } 121 \text {, de } 5 \text { de } \\
\text { outubro de } 1995\end{array}$ & $\begin{array}{l}\text { Regimento Interno do } \\
\text { Departamento Penitenciário do } \\
\text { Estado do Paraná }\end{array}$ & Paraná & $\begin{array}{l}\text { Assistência à gestante, parturiente e aos filhos das internas } \\
\text { desamparadas de até seis anos (Art. 20). }\end{array}$ \\
\hline $\begin{array}{l}\text { Constituição do Estado do } \\
\text { Rio Grande do Sul de } 1989\end{array}$ & & $\begin{array}{l}\text { Rio Grande } \\
\text { do Sul }\end{array}$ & $\begin{array}{l}\text { Obrigatoriedade de creche, em local anexo e independente, para } \\
\text { menores de até seis anos de idade (Art. 139). }\end{array}$ \\
\hline
\end{tabular}

unidades de prestação de serviços de assistência à saúde e psicossocial à presa, é organizado de maneira uniforme, por meio de Decretos do Poder Executivo. A regulamentação nesse sentido pode favorecer o acesso à saúde dessas mulheres e crianças na medida em que estabelece fluxos e obrigações para a Administração Penitenciária e no sistema de saúde local (Tabela 4).

Portanto, há uma considerável disparidade entre as regulamentações. Essa heterogeneidade e ausência de regulamentação da situação da criança com a mãe acentua o caráter discricionário imputado à direção dos estabelecimentos penais. Nesse sentido, o Estado de São Paulo se destaca como o estado que mais define as regras desses estabelecimentos, mesmo que as normas estabelecidas não respondam satisfatoriamente às necessidades das presas e seus filhos, como apontam entidades de defesa de direitos 23 .

As constituições estaduais fazem referência à creche como local de permanência da criança em estabelecimentos prisionais femininos, notadamente no período de amamentação. Assim, seguem, de certo modo, o artigo 5o, inciso L, da Constituição Federal, aplicando de forma generalizada o conceito de creche, e não no sentido estabelecido na Lei de Diretrizes e Bases para a
Educação Nacional (Lei no 9.394/96). Já a LEP estabelece o berçário, como o local onde as presas possam amamentar e cuidar de seus filhos, até seis meses de idade; e a creche para abrigar crianças maiores de 6 (seis) meses e menores de 7 (sete) anos, na situação de desamparo familiar. Aliás, uma interpretação meramente literal pode levar a uma inadequada limitação do direito à convivência entre mãe/filho, a sua função de aleitamento, esvaziando o conteúdo normativo garantista desta convivência. $\mathrm{O}$ direito à amamentação deve pressupor o reconhecimento da mulher presa como sujeito de direitos, e compreender o vínculo entre mãe e filho como muito mais amplo do que só o ato de dar alimentação à criança, ou de um local para simplesmente abrigar aquelas crianças por ausência de condições dos familiares.

\section{Conclusão}

A regulamentação acerca do direito das mães e seus filhos durante o aprisionamento apresenta alguns pontos de tensão, principalmente no tocante ao período de permanência e aos critérios adotados para a convivência com as crianças. A 
Tabela 4

Legislação do Estado de São Paulo, que contempla direitos para mães presas com seus filhos.

\begin{tabular}{|c|c|c|}
\hline Título & Ementa & Destaques (artigos) \\
\hline Constituição do Estado & & Previsão de creches e adequada assistência aos filhos de \\
\hline de São Paulo de 1989 & & presidiárias, durante o período de amamentação (Art. 286). \\
\hline Decreto no 13.412 , de & Dispõe sobre a organização dos estabelecimentos & Atribuições dos Setores de Creche (Art.156). \\
\hline 13 de março de 1979 & Penitenciários do Estado e dá providências correlatas. & \\
\hline Decreto no 43.277 , de & Reorganiza os estabelecimentos penais da Secretaria da & Atribuições e condições para abrigar e cuidar dos filhos das \\
\hline 3 de julho de 1998 & Administração Penitenciária e dá providências correlatas. & presas Unidades de atendimento de saúde (Art. 30, §2o ). \\
\hline Decreto no 47.607, de & Transfere a Cadeia Pública que especifica, altera a sua & Atribuições para o atendimento de saúde das crianças, \\
\hline 28 de janeiro de 2003 & $\begin{array}{c}\text { denominação para Penitenciária Feminina de Ribeirão Preto, } \\
\text { dispõe sobre sua organização. }\end{array}$ & filhos de presas (Art. 14, XXII a XXVI). \\
\hline Decreto no 48.002 , de & Cria e organiza, na Secretaria da Administração & Atribuições para o atendimento de saúde das crianças, \\
\hline 7 de agosto de 2003 & Penitenciária, a Penitenciária Feminina de Franco da Rocha & filhos de presas (Art. 14, XXII a XXVI). \\
\hline & e dá providências correlatas. & \\
\hline Decreto no 51.816 , de & Reorganiza a Penitenciária Feminina Sant'Ana e & Atribuições para o atendimento de saúde em relação aos \\
\hline 17 de maio de 2007 & dá providências correlatas. & filhos das presas (Art. 11, p. único). \\
\hline Decreto no 52.071, de & Reorganiza a Penitenciária Feminina de Ribeirão Preto e & Atribuições do Núcleo de Reintegração e Atendimento à \\
\hline 17 de agosto de 2007 & dá providências correlatas. & Saúde em relação aos filhos das presas (Art. 9o̊, p. único). \\
\hline Decreto no 56.080 , de & Classifica as unidades prisionais da Secretaria da & Atribuições do Núcleo de Atendimento à Saúde em relação \\
\hline \multirow[t]{3}{*}{10 de agosto de 2010} & Administração Penitenciária para fins de concessão da & aos filhos das presas (Art. 11, p. único). \\
\hline & Gratificação por Comando de Unidade Prisional e & \\
\hline & dá providências correlatas. & \\
\hline Decreto no 56.833 , de & Cria e organiza, na Secretaria da Administração & Atribuições do Centro de Reintegração e Atendimento à \\
\hline 14 de março de 2011 & $\begin{array}{c}\text { Penitenciária, a Penitenciária Feminina II de Tremembé e } \\
\text { dá providências correlatas. }\end{array}$ & Saúde em relação aos filhos das presas (Art. 10, p. único). \\
\hline Decreto no 56.935 , de & Cria e organiza, na Secretaria da Administração & Atribuições do Centro de Reintegração e Atendimento à \\
\hline 15 de abril de 2011 & $\begin{array}{l}\text { Penitenciária, a Penitenciária Feminina de Tupi Paulista e } \\
\text { dá providências correlatas. }\end{array}$ & Saúde em relação aos filhos das presas (Art. 10, p. único). \\
\hline Decreto no 57.185, de & Reorganiza, na Secretaria da Administração Penitenciária, as & Atribuições do Centro de Reintegração e Atendimento à \\
\hline 2 de agosto de 2011 & $\begin{array}{c}\text { Penitenciárias Femininas da Capital e de Campinas e } \\
\text { dá providências correlatas. }\end{array}$ & Saúde em relação aos filhos das presas (Art. 10, p. único). \\
\hline Decreto no 57.187, de & Altera a denominação da Penitenciária Feminina & Atribuições do Centro de Reintegração e Atendimento à \\
\hline 2 de agosto de 2011 & $\begin{array}{l}\text { "Dra. Marina Marigo Cardoso de Oliveira" do Butantã, } \\
\text { dispõe sobre sua organização e dá providências correlatas. }\end{array}$ & Saúde em relação aos filhos das presas (Art. 10, p. único). \\
\hline Decreto no 57.548 , de & Reorganiza, na Secretaria da Administração Penitenciária, a & Atribuições do Núcleo de Reintegração e Atendimento à \\
\hline 29 de novembro de & Penitenciária Feminina "Santa Maria Eufrásia Pelletier" de & Saúde em relação aos filhos das presas (Art. 9o, p. único). \\
\hline 2011 & Tremembé e dá providências correlatas. & \\
\hline Decreto no 58.172 , de & Cria e organiza, na Secretaria da Administração & Atribuições do Centro de Reintegração e Atendimento à \\
\hline 28 de junho de 2012 & $\begin{array}{l}\text { Penitenciária, a Penitenciária Feminina de Pirajuí e dá } \\
\text { providências correlatas. }\end{array}$ & Saúde em relação aos filhos das presas (Art. 10, p. único). \\
\hline
\end{tabular}

ausência de regulamentação específica que estabeleça um procedimento decisório claro, com definição do fluxo, das autoridades competentes e dos parâmetros a serem aplicados homogeneamente em todas as unidades fragiliza a garantia de direitos. Estudos já referidos registram a diversidade de atos arbitrários da autoridade penitenciária, e apontam aspectos negativos dessa desregulamentação, como a dificuldade de res- ponsabilização dos agentes estatais, ausência de medidas preventivas e coibitivas das violências institucionais, entre outras relacionadas à melhoria das condições gerais para a convivência no cárcere.

A previsão constitucional do direito à amamentação no cárcere foi instrumentalizada na LEP, garantindo-se a permanência da criança por, "no mínimo", seis meses. A Resolução 
CNPCP no 04/2009, confere o direito à convivência até um ano e seis meses e, após este período, um "processo gradual de separação" de até seis meses. Diante da extrema vulnerabilidade das pessoas envolvidas e da natureza fundamental deste direito, exige uma interpretação equitativa e sistêmica das normas a serem aplicadas, com primazia da norma mais favorável aos sujeitos em situação de vulnerabilidade, com o objetivo de garantir sua máxima efetividade. Portanto, há que se conferir primazia à regra mais benéfica estabelecida pelo Ministério da Justiça.

Além disso, as garantias de unidade materno-infantil, da convivência entre mãe e filho, e da manutenção de vínculos familiares devem estar associadas à implantação de políticas públicas que permitam a titulação e vivência desses direitos durante o encarceramento, bem como condições concretas de (re)inserção social de forma digna e justa, considerando o perfil socioeconômico da população carcerária e de suas famílias.

Reitera-se que as presas provisórias constituem $40 \%$ do total da população feminina carcerária e a maioria responde por condutas menos gravosas relacionadas ao tráfico de drogas. Portanto, é importante insistir que os avanços na legislação, tanto no âmbito processual como quanto à execução da pena, permitem a utilização de meios alternativos à prisão, certamente menos traumáticos às crianças recém-nascidas e suas famílias. Para tanto, é necessária a ampliação do acesso à assistência jurídica e ao uso dos recursos disponíveis, tornando efetivas as normas legais.
A legislação é um instrumento importante na garantia de direitos, porém, no contexto brasileiro, não se mostra suficiente para assegurar os direitos reprodutivos e parentais das mães com seus filhos, que permanecem dentro e fora das prisões. É certo que a produção adequada de leis deve ser acompanhada por políticas públicas eficazes e inclusivas, com instâncias e procedimentos fiscalizatórios eficientes, que consigam abarcar de maneira integral as necessidades desta parcela extremamente vulnerável da população brasileira.

É urgente o resgate da cidadania e da saúde das mulheres presidiárias e seus filhos. Um primeiro passo é a visibilidade da questão da maternidade e das crianças em situação de carcerária, bem como, o reconhecimento da importância da garantia dos direitos reprodutivos e parentais. Um segundo aspecto é a formulação de uma legislação adequada e favorável à saúde feminina e infantil, com clara responsabilização dos entes e agentes estatais e dos procedimentos a serem adotados no cotidiano carcerário nessas situações, reduzindo espaços de discricionariedade da autoridade penitenciária, e estabelecendo critérios universais para o acesso a direitos. $\mathrm{O}$ alcance do almejado bem estar deste segmento depende, ainda, de uma mudança de olhar da sociedade sobre as pessoas encarceradas, que reduza o preconceito e a discriminação, e estimule a solidariedade social. Acreditamos que só assim as vulnerabilidades dessas mulheres e suas famílias possam ser reduzidas. 


\section{Resumen}

Este estudio analiza las conexiones entre la salud, derechos humanos, legislación y políticas públicas, partiendo de una investigación documental, realizada a nivel federal y en los estados de Río Grande do Sul, Mato Grosso, Paraná y São Paulo, sobre las garantías jurídicas de las mujeres presas y sus hijos. El estudio pretende instrumentalizar una actuación garantista de los agentes públicos y dar visibilidad a esta problemática, frente a la extrema vulnerabilidad e invisibilidad jurídica y administrativa existente. Se identificaron 33 normas legales, con puntos de tensión, como la posibilidad de arresto domiciliario y disparidades en cuanto a los términos y condiciones de la estancia de los niños en el sistema penitenciario. La garantía constitucional del derecho a la lactancia materna se refleja en las regulaciones identificadas. No obstante, hay ausencias de otros aspectos de la maternidad en la cárcel, que se traduce en una doble pena para las mujeres, extendida arbitrariamente a sus hijos. Es necesaria la ampliación y ejecución efectiva de las regulación existente para prevenir y frenar las violaciones de los derechos.

Prisiones; Salud Materno-Infantil; Derechos

Reproductivos; Legislación

\section{Referências}

1. Coordenação da Comissão Especial Projeto Mulheres, Diretoria de Polícias Penitenciárias. Mulheres presas: dados gerais. Brasília: Departamento Penitenciário Nacional, Ministério da Justiça; 2011.

2. United Nations Population Information Network. A/CONF.171/13: report of the ICPD (94/10/18). http://www.un.org/popin/icpd/conference/of feng/poa.html (acessado em 07/Mai/2014).

3. United Nations. Fourth World Conference on Women. http://www.un.org/womenwatch/daw/ beijing/platform/ (acessado em 07/Mai/2014).

4. Victora CG, Aquino EML, Leal MC, Monteiro CA Barros FC, Szwarcwald CL. Maternal and child health in Brazil: progress and challenges. Lancet 2011; 377:1863-76.

5. United Nations. United Nations rules for the treatment of women prisoners and non-custodial measures for women offenders (the Bangkok Rules). http://www.ohchr.org/Documents/Professional Interest/BangkokRules.pdf (acessado em 07/Mai/ 2014).

\section{Colaboradores}

M. Ventura colaborou na concepção da ideia central do trabalho, análise dos dados, redação e revisão do texto. L. Simas participou da coleta e análise dos dados, construção do banco de dados e redação do texto. B. Larouzé contribuiu na concepção da ideia central do trabalho, na redação e revisão do texto final.

\section{Agradecimentos}

À Maria do Carmo Leal, Alexandra Sanches, Vilma Diuana de Castro e Michelly Ribeiro Baptista, pelas preciosas sugestões no desenvolvimento de todo trabalho. Ao Ministério da Saúde, Departamento de Assistência e Promoção à Saúde (DAPS), e a Escola Nacional de Saúde Pública Sergio Arouca, Fundação Oswaldo Cruz (ENSP/ Fiocruz) pelo apoio à pesquisa.
6. Kahn T. Sistema prisional brasileiro: algumas considerações internacionais e perspectivas para os próximos anos. Revista do Ilanud 1997; 3:43-50.

7. Brasil. Lei no 7.210, de 11 de julho de 1984. Institui a Lei de Execução Penal. Diário Oficial da União 1984; 13 jul.

8. Lejarraga H, Berardi C, Ortale S, Contreras MM, Sanjurjo A, Lejarraga C, et al. Crecimiento, desarrollo, integración social y prácticas de crianza en niños que viven con sus madres en prisión. Arch Argent Pediatr 2011; 109:485-91.

9. Rita RPS. Mães e crianças atrás das grades: em questão o princípio da dignidade da pessoa humana [Dissertação de Mestrado]. Brasília: Universidade de Brasília; 2006.

10. Cartaxo RO, Costa GMC, Celino SDM, Cavalcanti AL. Panorama da estrutura presidiária brasileira. Rev Bras Promoç Saúde 2013; 26:266-73.

11. Dotti RA. Princípios fundamentais do Direito Penal Brasileiro. http://www.buscalegis.ufsc.br/revistas/ files/anexos/11966-11966-1-PB.pdf (acessado em 29/Abr/2013). 
12. Ferreira Filho MG. Comentários à Constituição Brasileira de 1988. São Paulo: Saraiva; 1990.

13. França Junior I, Ayres JRCM. Saúde pública e direitos humanos. In: Forte PAC, Zoboli ELC, organizadores. Bioética e saúde pública. São Paulo: Centro Universitário São Camilo/Edições Loyola; 2003. p. 63-70.

14. Piovesan F, Pirotta WRB. A proteção dos direitos reprodutivos no direito internacional e no direito interno. In: Piovesan F, organizador. Temas de direitos humanos. 2a Ed. São Paulo: Max Limonad; 2003. p. 237-76.

15. Carvalho AI, Buss PM. Os determinantes sociais na saúde, na doença e na intervenção. In: Giovanella L, Escorel S, Lobato LVC, Noronha JC, Carvalho AI, organizadores. Políticas e sistemas de saúde no Brasil. Rio de Janeiro: Editora Fiocruz; 2008. p. 141-66.

16. Sigerist HE. Doença e lei. In: Sigerist HE, organizador. Civilização e doença. São Paulo: Editora Hucitec/Sobravime/Campinas: Sindmed; 2011. p. 96-121.

17. Buss PM, Pellegrini Filho A. A saúde e seus determinantes sociais. Physis (Rio J.) 2007; 17:77-93.

18. Joint United Nations Programme on HIV/AIDS; Inter-Parliamentary Union. Handbook for legislators on HIV/AIDS, law and human rights. Action to combat HIV/AIDS in view of its devastating human, economic and social impact. Geneva: Joint United Nations Programme on HIV/AIDS; 1999.
19. Cook R, Dickens BM, Fathalla MF. Saúde reprodutiva e direitos humanos: integrando medicina, ética e direito. Rio de Janeiro: Cepia \& Oxford; 2004.

20. Gruskin S, Tarantola D. Um panorama sobre saúde e direitos humanos. In Paiva V, Ayres JR, Buchalla $\mathrm{CM}$, organizadores. Vulnerabilidade e direitos humanos: prevenção e promoção da saúde: da doença à cidadania. Curitiba: Juruá; 2012. p. 23-42.

21. Canfão AO. Métodos de interpretação jurídica à luz do horizonte hermenêutico. Revista Jurídica 2013; (158). www.revistas.unifacs.br/index.php/ redu/article/download/2715/1967 (acessado em 25/Ago/2014).

22. Departamento de Ações Programáticas Estratégicas, Secretaria de Atenção à Saúde, Ministério da Saúde. Legislação da saúde no sistema penitenciário. Brasília: Ministério da Saúde; 2010. (Série E. Legislação de Saúde).

23. Pastoral Carcerária; CONECTAS Direitos Humanos; Instituto Sou da Paz. Relatório sobre mulheres encarceradas no Brasil. http://carceraria.org. $\mathrm{br} / \mathrm{wp}$-content/uploads/2012/09/relatorio-mu lherese-presas_versaofinall.pdf (acessado em 29/ Abr/2013).

Recebido em 13/Jun/2014

Versão final reapresentada em 18/Set/2014

Aprovado em 29/Set/2014 